\title{
Mo Yan's Life and Death Are Wearing Me Out: A Conceptual Integration Analysis
}

\author{
Omid Akhavan (Corresponding author) \\ Department of English, Vali-e-Asr University of Rafsanjan, Iran \\ E-mail: omidakhavan@outlook.com \\ Esmaeil Zohdi \\ Department of English, Vali-e-Asr University of Rafsanjan, Iran \\ E-mail:esmaeil_zohdi@yahoo.com
}

Received: 20-07-2014

doi:10.7575/aiac.ijalel.v.4n.1p.79
Accepted: $31-08-2014$

Published: 01-01-2015

\begin{abstract}
Cognitive linguistics is a modern school of linguistic thought that originated in the late seventies out of the work of a number of researchers who were interested in the relation of language and mind. It is a new linguistic paradigm which sees language not as an independent, self-sufficient system but as an instrument for organizing, processing, and conveying information. Recent studies and investigations in the field of cognitive linguistics have increased the range of possibilities for linguistic research regarding language and culture. Conceptual Integration Theory, proposed by Gilles Fauconnier and Mark Turner (2002), is a further development of this line of research. It is a basic mental operation which is central to human thought, imagination, and the way we think. Conceptual integration performs an important role in construction of meaning in everyday life, in science, and even in literature. Mo Yan's Life and Death Are Wearing Me Out (2006) is a historical fiction exploring China's development during the latter half of the twentieth century. The author himself asserts that the novel encapsulates his writing styles and reflects his exploration in the arts of novel writing. The present study examined the Conceptual Integration Theory in Mo Yan's Life and Death Are Wearing Me Out. It also demonstrated the way the author made use of personification and conceptual blending in order to create a satirical atmosphere and to criticize totalitarian states.
\end{abstract}

Keywords: Cognitive Linguistics, Conceptual Integration Theory, Life and Death Are Wearing Me Out, Mo Yan

\section{Introduction}

\subsection{Statement of the Problem}

At the point when confronted with problems, different individuals react in different ways; in addition, different groups of people likewise react in diverse ways. In the field of Literature, literary analyses draw upon a basis in literary theories. Then critical approaches developed as a means to understand the different ways individuals read and interpret texts. They are lenses through which we can observe and examine texts. Literary theories vary in the ways they incorporate the three components of literature - the writer, the reader, and the text.

On the one hand are those theories that concentrate on the text itself, for example, formalist and structuralist approaches; on the other hand, those that concentrate on the writer such as biographical and psychoanalytical approaches or reader like reader response approaches. Additionally, approaches such as historical and cultural find themselves somewhere between, integrating features of more than one component. There is nothing to say that one is superior to another or texts must be read by any of them, yet it is in some cases enjoyable to choose to read a text with one in mind and wind up with an entire new viewpoint on reading.

While there have been broad examinations concerning literary analyses, these examinations have not been carried out through the framework of cognitive linguistics. The aforementioned literary theories might be accommodated by applying a cognitive linguistic approach to literature. Cognitive linguistics is concerned with examining the relationship between human language and mind. It is a modern school of linguistic thought that emerged originally in seventies and developed in eighties out of discontent with formal approaches to language. The objective of cognitive linguistics is to see how individuals think, particularly through the study of language.

Conceptual Integration Theory (CIT), often called "blending," is a further development of this line of research. It is a basic cognitive process that occurs naturally. This process develops through the composition, completion and elaboration of mental spaces (Fauconnier \& Turner, 1998, pp. 133-187). According to Fauconnier and Turner, mental spaces are "small conceptual packets constructed as we think and talk" (1998, p. 138). Conceptual blending is a fundamentally distinctive approach to comprehend a belief or set of beliefs.

Moreover, Mark Turner (1998, p. 93) states that "Conceptual blending is a fundamental instrument of the everyday mind, used in our basic construal of all our realities, from the social to the scientific." It offers a remarkable approach to 
see how individuals use basic ideas to make new conceptual constructions and how those same conceptual constructions are used to structure other concepts. In this paper, the researcher would like to use conceptual blending to illustrate how meaning exists in the context of the words used and in the minds of the language users, rather than in the words themselves.

\subsection{Objectives}

This study was designed to present the notion of "blending." Furthermore, it argues that, in Mo Yan's Life and Death Are Wearing Me Out, conceptual blending depicts Mo Yan's critique of totalitarian state. Similarly, it was designed to examine the literary passages that create "blending" that is evident in Mo Yan's work. The aim of the present study is to examine the Conceptual Integration Theory in Mo Yan's Life and Death Are Wearing Me Out and to demonstrate how the author makes use of personification and conceptual blending in order to create satirical environment and to criticize totalitarian states.

Additionally, authentic textual examples will be used to illustrate the relationship these elements have to one another. Moreover, special attention will be given to the identification and characteristics of blending and how it is used by Mo Yan. Once identified, mapping and authentic textual examples will be offered. This study also seeks to provide reasonable answers to the following questions:

1. In what situations might a conceptual blending occur?

2. What's the interrelation of conceptual blending and personification?

3. How personification and conceptual blending create satirical atmosphere?

4. How personification and conceptual blending reveal Mo Yan's critique of totalitarian state?

\subsection{Methodology}

The present study is based on the library research that is a kind of research where the researcher gains the data from books and other references which have relationship with the object of investigation. Also, the theoretical framework of this study is based on the Conceptual Integration Theory (Fauconnier \& Turner, 1994; 1998, pp. 133-187; 2003). It will be applied to Mo Yan's 2006 novel entitled Life and Death Are Wearing Me Out which consists of fifty-eight chapters.

First, the book will be read in its entirety for content and context. Next, some complementary reading will be carried out with respect to the historical backdrop of the book and the time period about which it was written so as to have a clear idea of the historical implications. Then critical excerpts will be selected from throughout the book to further the examination of CIT. Discussed in detail in Fauconnier and Turner (1998, pp. 133-187), conceptual blending is a theoretical framework for investigating human information integration. It involves a set of operations for consolidating dynamic cognitive models in a network of mental spaces or partitions of speakers' referential representations.

Therefore, an illustrative model will be created as a visual representation of the blending. The models created are structurally similar to the previously illustrated model of Conceptual Integration Theory provided by Fauconnier and Turner (1998, p. 146). By identifying the blendings and representing them visually, an analysis of how these literary elements allow for Mo Yan's construction of a satirical environment will be carried out. Finally, the aforementioned illustrative models will serve as a vehicle for expressing the final results.

\subsection{Review of Literature}

The origins of conceptual integration theory lie in the research projects of Gilles Fauconnier and Mark Turner. Conceptual blending developed out of new thoughts regarding how individuals contemplate the world. The practice of blending theory claims to real life and practical situations. Dr. Tony Veale (2002, pp. 1-38) has investigated blending theory by examining political cartoons and historical literature. His investigation of pre-Hellenic and Hellenic Greece moved significantly further the idea that conceptual integration is surrounding us. He acclaims Fauconnier and Turner's case by stating, "Blend theory is an intriguing model of conceptual integration that is perhaps capable of revealing as much about human culture as human cognition" (2002, p. 5).

Veale argues that myths function to portray social, political and religious aspects of a society, and that the blends that arise from the myths reflects social combination of the examined culture. Blends that derived from his exploration incorporate things like polymorphized divinities who are given various names relying upon the city in which they are being adored or worshipped. Additionally, blends are evident in the cases where deities are considered to be the embodiment of concepts such as love, courage, war, and so forth. Also, blends are apparent in the situations where divinities are considered to be the embodiment of concepts such as love, courage, war, and so on.

In addition, Line Brandt and Per Brandt (2005, pp. 216-249) examined the blend that occurs in Grady, Oakley and Coulson's (1999, p. 32) example: "this surgeon is a butcher." On the one hand we have a surgeon, who is generally considered to practice with accuracy, sensitivity and kindness. On the other hand, a butcher is a person who slaughters certain animals in order to cut their meat off bones. Despite the fact that butchery may be viewed as a dirty or an undesirable job, one cannot accept that a butcher does not consolidate a certain level of accuracy, sensitivity and kindness into his/her job. The emergent structure in this blend is apparent in light of the fact that the utterance almost naturally illustrates the image of a surgeon that is famous for botching his or her operations, despite the fact that butchery has nothing to do with poor performance.

There have also been extensive examinations of conceptual integration theory over the past few years. Kémenes Árpád (2007, pp. 1-11) has examined conceptual blending in Sylvia Plath's poetry. He investigated the way in which 
metaphors are made and associated with one another in Sylvia Plath's poetry. He analyzes the metaphors within Fauconnier and Turner's blending theory, and gives many examples which help readers' understanding and interpretation of idiosyncratic metaphoric pairings. He claims that the increase in the number of an element in an input space can function as organizing frame for the input of a subsequent metaphor, and the fusion of the same input spaces can produce different emergent structures.

Margaret Freeman (2005, pp. 25-44) also investigated conceptual integration in Sylvia Plath's poetry. Her investigation demonstrates that conceptual blending theory can accommodate an integrated and coherent account of the cognitive mechanisms by which poetry is constructed and interpreted. She portrays the techniques and methodologies that the readers adopt to interpret a poem. Freeman even argues that the principles and techniques illustrated in blending theory are not new to the study of the poetry; she states that we have been utilizing them since Aristotle published the Poetics. Furthermore, she investigates the ways blending can highlight the processing of literary texts by applying the conceptual integration theory to the analysis of a poem. Although the conceptual integration theory has been applied to literary work alike in investigation, it has not been applied to the works of Mo Yan, especially his political novel entitled Life and Death Are Wearing Me Out. Moreover, an observational study would be beneficial in demonstrating the process by which a blend takes form in a literary text.

\subsection{Significance of the Study}

In recent years, there has been a growing interest on the part of literary scholars in the significant interdisciplinary activity indicating the confluence of cognitive psychology, neuroscience, linguistics, artificial intelligence, and the philosophy of mind: the cognitive sciences. The development of cognitive linguistics has improved the advancement of new relations between literature and linguistics. The agreement rising up out of these discussions is that cognitive science can help essentially to our understanding of literary texts in their historical contexts. In the same way that literary texts may serve as reasonable data for comprehending the principles of language structure and use, a linguistic approach to literature provides new viewpoints on literary production, interpretation, reception, and assessment.

Moreover, a cognitive linguistic approach to literary texts helps readers to increase their literary understanding in terms of how language and mind work together in construction of meaning in literature. A further critical case is that language reflects thought, and along these lines language itself is an indication of how individuals imagine the world, and the events that happen. Conceptual blending analysis is also useful in examining the role of conceptual tools in literary texts, since it provides an opportunity to analyze thought processes through language. Thus, the study of language can help us understand contemplations of individuals and the interpretations of the events. Knowledge conceived by cognitive science about such subjects as perception, representation, and concept formation can be recruited to support literary criticism conspicuously.

\section{Theoretical Background}

\subsection{Conceptual Integration Theory}

By the end of the 1990s, Mark Turner had developed Gilles Fauconnier's Mental Spaces Theory into a theory with much more extent of theoretical and contextual practicality known today as Conceptual Integration Theory. They remark on the pervasiveness of Conceptual Integration Theory in saying, "conceptual framing has been shown to arise very early in the infant and to operate in every social and conceptual domain" (Fauconnier \& Turner, 2003, p. 17). However, instances of conceptual blending could be met in distinct places, for example, in advertisements, books, newspapers, films, and so forth. But what is CIT really?

Conceptual blending is an appealing theory of how individuals conceptualize the world through making the connections among mental spaces of different sorts. This action is complicated, but then everybody does it everyday. Additionally, it indicates that the process of producing discourse is not a compositional one, instead, it incorporates the unfolding of a profusion of contexts, or cognitive areas, which restrain the referential and informative dimensions of an utterance or behavior. The conceptual integration theory integrates a few mental spaces into a network (called a conceptual integration network). At the point when the conceptual integration network is operational, the result is a Blended Space.

As Fauconnier and Turner illustrate, mental spaces are indicated by four circles and also elements within mental spaces are presented by points inside the circles in the basic blending diagram of a conceptual integration network. Although this chart illustrates a "static" representation of a conceptual blending, it is essential to perceive, as Fauconnier and Turner (2003, p. 46) assert, that "such a chart is truly simply a preview of an inventive and confounded methodology." Blends emerge out of networks of mental spaces. The basic blending network comprises of four mental spaces: two input spaces, a generic space, and the blended space. According to Coulson (2006, p. 23), "a new space is . . set up when utterances concern objects or events that require different background assumptions."

Metaphorical expressions in discourse are of exactly this kind; they include spaces which hold components belonging to two different situations with distinctive background frames or assumptions. As figurative discourse unfolds, then, a space is made for each situation. The established spaces are Input Space 1 and Input Space 2. Cross-space mapping allows for counterpart connections between elements of the input spaces. These counterpart connections might be of various types, generally known as vital relations. Fauconnier and Turner (2003, pp. 89-111) determined various vital relations including character, identity, time, and space. Dashed lines linking the components within the spaces account for conceptual projections across the network. 
The next mental space that is created along with the two input space is the Generic Space. It consists of elements which is shared to the components in the input spaces. In other words, "at any moment in the construction of the network, the structure that inputs seem to share is captured in a generic space" (Fauconnier \& Turner, 2003, p. 47). Components in the generic space make the counterpart connection with components in the input spaces. The generic space might additionally be projected back to from the blended space. We can consider structure in the generic space regarding semantic classifications which form the abstract representation in discourse of a given situation. For instance, with respect to who did what to whom, where, and how.

Finally, the Blended Space with its "emergent structure," illustrated by a square inside the blended space, is established by means of blending operations. It accepts structure from both the input space, and is considered to be the product of conceptual integration which combines elements from the input spaces in order to create a new concept or situation. "In blending, structure from two input spaces is projected to a separate space, the 'blend.' The blend inherits partial structure from the input spaces, and has emergent structure of its own"(Fauconnier \& Turner, 2003, p. 113). The blended space likewise gets structure from the generic space.

"Generic spaces and blended spaces are related: blends contain generic structure captured in the generic space"(Fauconnier \& Turner, 2003, p. 47). The Blend Space contains more information than either of the two inputs. The emergent structure also has a unique structure to the blend. It is composed of a completely novel structure of elements which are not copied directly from the input spaces. Figure 1 (Fauconnier \& Turner, 1998, p. 153) clearly illustrates the distinct spaces' interconnectivity.

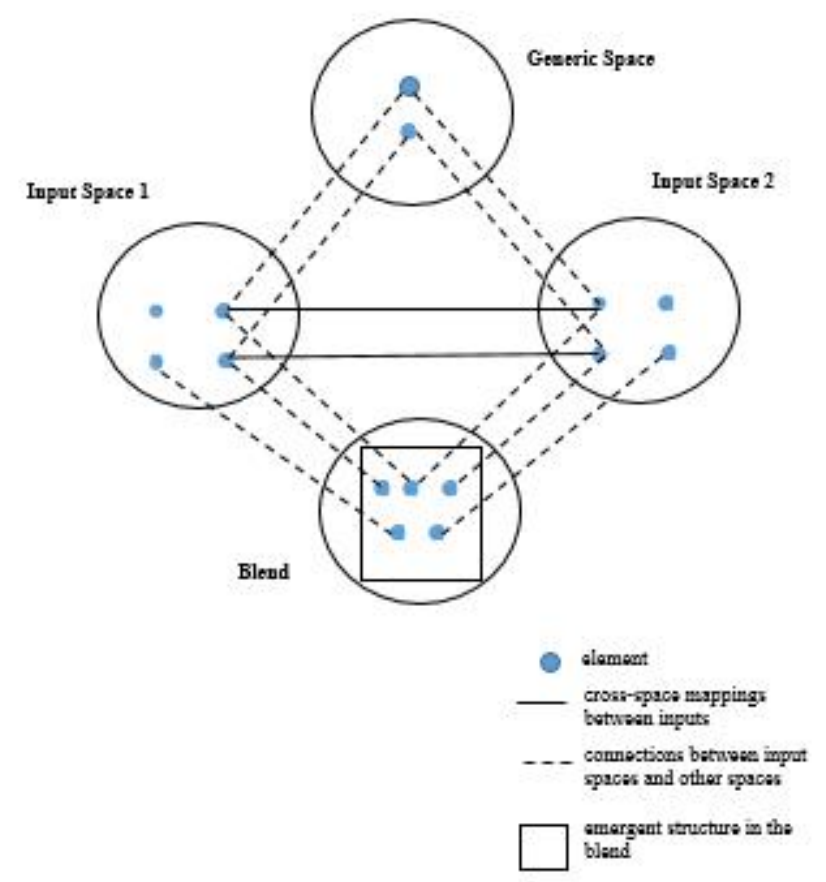

Fig̣. 1. Schematic blauding disgrum

\subsection{Personification}

Personification has traditionally been an important aspect of narratives; Aristotle describes personification as: "Homer's common practice of giving metaphorical life to lifeless things" (qtd. in Paxson, 1994, p. 12). Demetrius describes personification as:

"representing an abstract person as present, or in making a mute thing or one lacking form articulate, and attributing to it a definite form and a language of certain behavior appropriate to its character.... Personification may be applied to a variety of things, mute and inanimate. It is most useful in the division under amplification and in appeal to pity" (qtd. in Paxson, 1994, pp. 13-14).

Also, Peachamian states that in personification "poets and orators do attribute to things which are without life, not only life, but also reason and affection, and sometime speech" (qtd. in Paxson, 1994, p. 24). In addition, Paul de Man has given more importance to personification in describing it as "the master trope of poetic discourse" (qtd. in Paxson, 1994, p. 1). However, personification has still been an appealing subject matter of studies all over the world. It is broadly utilized within different linguistic styles: natural, political, and literary language style. Personification, a crucial technique could be utilized by writers to give their works an incredible value, and let the characters reveal their feelings. 
Personification has long been taken for granted as the rhetorical device which helps obtain impressiveness and vividness of expression by providing the animal, object or situation with human traits, feelings or activities; or by simply animating the inanimate (Lakoff \& Johnson, 2003, p. 28). In the same way, Jonathan Charteris-Black offers a definition of personification; he claims that it is, "referring to something that is inanimate using a word or phrase that in other contexts refers to something that is animate" (2005, p. 15). He likewise provides the words "motherland" and "fatherland" as examples of personification.

However, should we consider personification a type metaphor? If we examine Fauconnier and Turner's (1998, p. 168) example of personification: "Death is a reaper," through the framework of conceptual blending: There are two input spaces, "death" and "farmer." The output of this connection is a new blended space, death as a life-cutter. Hence, this blend results in a metaphor and since "death" could not be taken into account as a human entity, we are confronting with a case of personification. To further the nature of personification Lakoff and Johnson remark on it. They assert: "Perhaps the most obvious ontological metaphors are those where the physical object is further specified as being a person. This allows us to comprehend a wide variety of experiences with nonhuman entities in terms of human motivations, characteristics and activities" (2003, p. 33).

This notion is of particular interest considering the task at hand in this exploration of Life and Death Are Wearing Me Out. In next section authentic textual passages will be provided with respect to different characteristics that the animals possess. The excerpts offered hold to be true in considering Lakoff and Johnson's claim that each instance of personification endows a given non-human entity with different human characteristics. These excerpts elucidate the malleable nature of theories like conceptual blending and personification.

\section{Discussion}

\subsection{Personification in Life and Death Are Wearing Me Out}

Life and Death Are Wearing Me Out is a fiction written with instances of personification. As discussed at length in section 2.2, personification refers to situations in narratives where non-human beings are endowed with human traits. This section deals with identification and examination of various excerpts from the novel that are used to personify the major character. These personified instances are utilized in the novel by the author so as to establish conceptual blending.

(1)

'I am not a donkey!' I roared. 'I am a man! I am Ximen Nao!' But my throat felt exactly the way it had when the two blue-faced demons had throttled me. I couldn't speak no matter how hard I tried. Despair, terror, rage. I spat out slobber, sticky tears oozed from my eyes. (Yan, 2006, p. 8)

(2)

I grew into a mature donkey by eating sorghum porridge. Yingchun made it for me; she's the one I can thank for growing up... I could see her bulging breasts when she fed me; they were filled with light blue milk. I knew the taste of that milk, because I'd drunk it. It was delicious, and her breasts were wonderful. (Yan, 2006, p. 11)

Passages (1) and (2) are excellent examples which show the way in which a donkey is personified as well as given more advanced human traits. In these passages the donkey is described in terms of its stubbornness and expressing emotions and feelings like despair, anger, and grieveness. These passages even touch on the donkey's astoundingly human ability to judge and to make decisions in different situations. It also has the ability to understand the taste of the milk whether it is delicious or not. These excerpts also demonstrate donkey's ability to memorize as well as the ability to verbally express the memorized information. In these passages it is clear that the donkey contains full range of human cognitive capacities; the ability to dream, forget, reason, remember, and so forth.

(3)

Now, Ximen Ox, I should relate what you were doing on that market day. At first, you meekly followed behind my dad, matching him step for step. But your glorious image and your obedient behavior seemed odd to people, especially to me. You were a spirited animal that had displayed extraordinary behaviors in prior months and years. (Yan, 2006, p. 115)

(4)

I'll be honest with you. When she pressed my head up against her breast, my little pecker stiffened... I drifted into a fantasy world, wishing that Wu Qiuxiang would marry Hezuo, the daughter with the boyish haircut, to Jinlong, and let me marry Huzhu. (Yan, 2006, p. 124)

In passages (3) and (4) the personified ox is depicted as an animal that possesses humans' characteristics such as glory, gentleness, honesty, and having wishes. It also knows how to behave the same as human beings and this is exactly what was odd to the people. Passage (4) is one of the most important excerpts which extremely expresses the deep feelings and emotions of the ox. In this passage the ox is drifted into a fantasy world where it wishes to marry Huzhu. The ability to make such an imaginative and fantastic world through an animal clearly demonstrates that this animal is endowed with human characteristics and therefore is personified. 
(5)

I shoved a couple of apricot leaves up my nose. I thought they'd be bringing over some pretty little pigs to keep me company and supply the future king of pigs with a harem... I didn't have the heart to look any longer, but their funny accents piqued my curiosity. (Yan, 2006, p. 154)

(6)

Needless to say, as a pig with extraordinary intelligence, my first concern was self-protection. So when I saw them carrying Diao Xiaosan my way, I knew what they had in mind. I quickly and quietly sprawled atop a pile of dry grass and leaves in a corner of the wall to pretend I was asleep. (Yan, 2006, p. 157)

In passages (5) and (6) the pig is characterized as an intelligent, sensible, and smart animal that is able to think and express its feelings. The pig's most salient quality is the ability to understand its own surrounding events and producing appropriate reactions in different situations. In passage (5) the pig is thinking about a kingdom in which some pretty little pigs keep it company and supply the future king of pigs with a harem. This perspective shows humanely ambitions and also the greedy faces of human beings that the pig is endowed with them.

(7)

We wrapped our arms around each other and began to move in the moonlight like fish tumbling in the water. We made love with tears of gratitude in our eyes. Our bodies seemed to float up and out the window... On our way out we stood in the gateway and, feeling intense nostalgia, yet seemingly with no wistfulness at all, took a long look inside. Then we headed out to the plot of land, where the moon hung low waiting for us. (Yan, 2006, p. 344)

(8)

I hesitated momentarily before shaking my head...My hatred is all gone, Great Lord! (Yan, 2006, p. 345)

In Passages (7) and (8) the dog is able to express its feelings as well as its ability to think, judge, and to forgive. One of the most obvious features in which the reincarnated animals are endowed throughout the novel is their human-like cognitive capacity. They are able to imagine, dream, wish, and so on. In these passages what is clear is that the author creates imaginative scenes through giving human traits and characteristics to the dog. The dog is capable of making love, feeling intense nostalgia, and even forgiving one of the human characters of the novel. These situations obviously demonstrate that the dog is personified in this novel.

(9)

As she sang, Fenghuang tossed the straw hat to the monkey, who nimbly put it on his head. Next she tossed him the pipe; he jumped up and put it in his mouth... with his head rocking from side to side and his eyes darting, he looked like an old man out for a stroll, and was rewarded with laughter and applause. (Yan, 2006, p. 350)

The monkey screeched and sprang at him, but wound up doing a somersault, thanks to the chain around his neck... The monkey stayed put, glowering at anyone who tried to come close. When Kaifang and several of his men ran up, they were stopped by the monkey's fearful screeches and threatening gestures. (Yan, 2006, p. 354)

Passages (9) and (10) depict the other situations in which human characteristics such as thinking and hatred are given to non-human beings. These passages also illustrate the monkey's ability to imitate human behaviors and gestures which it makes in order to catch people's attention. In passage (9) the monkey is given more human traits and it can be compared to a clown in a circus. It wears funny clothes and makes people laugh by performing tricks and behaving in a silly way. Therefore, the application of personification to the monkey could be seen in theses passages.

As it is discussed in previous section, personification refers to situations in which human characteristics are attributed to an abstract quality, animal, or inanimate object. In Starkey's (2004, p. 110) words:

Personification is the technique where the author gives non-human characters human thoughts, speech, and feelings... Without personification, the main character, who is an animal, would not be able to express his feelings...With personification, a non-fictional event can be fictionalized... It allows the characters to express their feelings, helps the story unfold, and makes it more enjoyable.

Examination of the above excerpts clearly demonstrate the way Mo Yan personified the major character of the book. By using personification the author paves the way for establishing conceptual blending which is the main discussion of this study. Therefore, a closer examination of the above excerpts will be done in the following section in order to elucidate the application of conceptual integration to the novel. 
"A writer should bury his thoughts deep and convey them through the characters in his novel" (Yan, qtd. in "Mo Yan").

As it is discussed at length in section 2.1, CIT is a basic mental operation, which is essential for the simplest kinds of thought and it is an unconscious activity embedded in every aspect of human life. Creating an integration network is a process which, according to Fauconnier and Turner (2003, p. 42), "involves setting up mental spaces, matching across spaces, projecting selectively to a blend, locating shared structures, projecting backwards to inputs, recruiting new structure to the inputs or the blend, and running various operations in the blend." Furthermore, "Establishing mental spaces, connections between them and blended spaces gives us global insight, new meaning and human-scale understanding"(2003, p. 92). However, a conceptual integration network can contains several input spaces and also of multiple blended spaces. Now, I will examine the excerpts presented in the section 3.1 to illustrate the application of conceptual integration to the novel.

In passage (1) mental spaces required for construction of blending can clearly be distinguished and are as follows: Input Space 1 which contains the animal (donkey) and its own physical abilities and cognitive capacities. Next, Input Space 2 contains human and his own physical abilities as well as cognitive capacities. The Generic Space of blending contains such components as mammals, brain capacities and physical abilities specific to the species, and so forth.

Finally, the blended space shows the way Mo Yan bestows a myriad of cognitive traits and characteristics upon the donkey and also the other animals of the novel, and it is through these personified characteristics, which could be observed as the blended space's emergent structure. In the blended space it can be seen, based on the words from passage (1), that the donkey is endowed with human capacities such as desire to communicate as well as the ability to express emotions and feelings like despair, anger, and grieveness. Here we depict an animal in our mind that is able to express its feelings verbally. In next passages it becomes quite evident that the reincarnated animals possess the full range of human emotion and cognitive capacity i.e. reason, logic, fear, sorrow, concern, love, and so on.

Passages (2)-(4) depict other situations in which conceptual integration occurs. Similar to passage (1) the mental spaces required for construction of blending are as follows: Input Space 1 which contains the animals (donkey and ox) and their own physical abilities and cognitive capacities. Next, Input Space 2 contains human and his own physical abilities as well as cognitive capacities. The Generic Space of blending contains such components as mammals, brain capacities and physical abilities specific to the species. Finally, the emergent structure in the blended space illustrates that the animals are endowed with human characteristics such as glory, gentleness, honesty, and having wishes.

Passages (5) and (6) also provide other great examples of the situations in which blending occurs throughout the novel, and, as the above passages, assert a simple and general explanation of the human characteristics and abilities that the animals possess. The required mental spaces for construction of blending in these examples can be depicted the same as the above examples; Input Space 1 which contains the animal (pig) that possesses, at least to a certain degree, human characteristics. Input Space 2 contains human and his own physical abilities as well as cognitive capacities. Once again, The Generic Space of blending contains such components as mammals, brain capacities and physical abilities specific to the species. Therefore, the emergent structure in the blended space obviously demonstrates that the animals are endowed with human capacities.

Passages (7)-(10) illustrate the other situations in which blending takes place in the novel. The required mental spaces for construction of blending in these examples can be presented in the same way as the former examples. In these examples the malleability of Conceptual Integration Theory is illustrated. Many would surely argue that these are clearcut examples of personification in which human traits are given to that which is not human, or as Charteris-Black explains it "referring to something that is inanimate using a word or phrase that in other contexts refers to something that is animate" (2005, p. 15). However, it can be systematically argued as well that these are obvious cases of conceptual integration.

Fauconnier and Turner have vigorously advocated CIT and its pervasiveness in everyday life. However, it is difficult to rebut the claim that these cases cannot be considered conceptual integration and personification alike. Conceptual blending has proven to be a highly intriguing theory with which to model human cognizing. Elements in mental spaces are blended in a subconscious process that is considered to be pervasive to everyday thought and language. Insights achieved from these blends form the products of creative thinking.

As it is illustrated in figure 2, the emergent structure in the blended space obviously demonstrates that the animals are endowed with human capacities. It is clear that they contain full range of human capacities such as the ability to reason, dream, wish, remember, and so on. In addition, one of the most astonishing qualities of the reincarnated animals in the novel is their ability to express their wishes and desires verbally. Figure 2 shows a visual representation of the Conceptual Integration (blending) in Life and Death Are Wearing Me Out. The model created is identical in structure to the previously represented model of Conceptual Integration Theory provided by Fauconnier and Turner (1998, p. 153). 


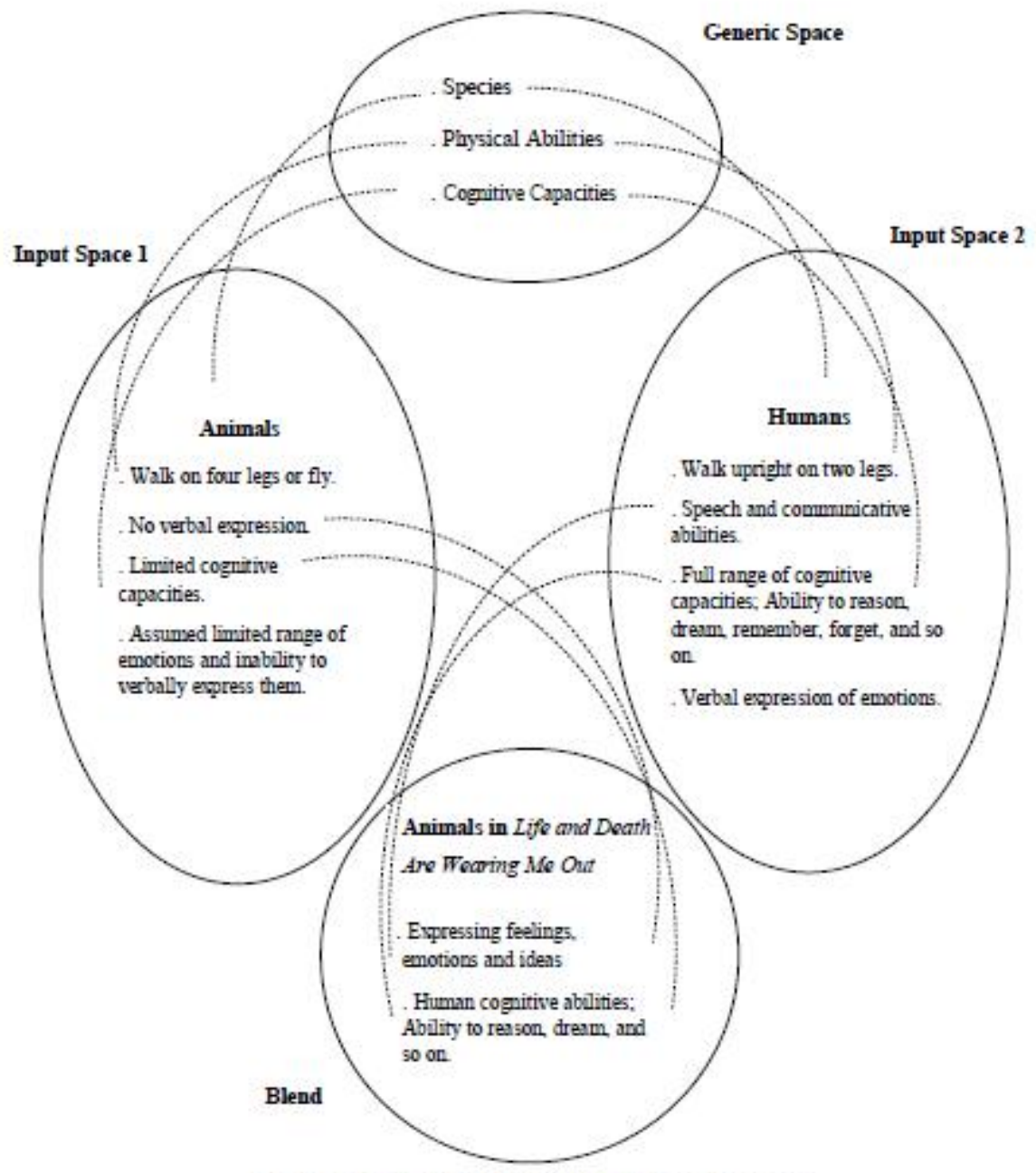

Fig. 2. The blending in Life and Death Are Wearing Me Out

Then the identified situations in which blendings occur and their visual representation serve as a vehicle for discussing of how Mo Yan makes use of personification and blending in Life and Death Are Wearing Me Out so as to create satirical atmosphere and to criticize totalitarian states.

\subsection{Personification, Blending, and Mo Yan's Critique}

"A writer should express criticism and indignation at the dark side of society and the ugliness of human nature, but we should not use the one uniform expression" (Yan, qtd. in "Mo Yan").

In Life and Death Are Wearing Me Out, Mo Yan utilizes the concepts investigated in the previous two sections as a means of creating the satirical message. It could be seen that the two concepts investigated in this study (personification, and conceptual integration) are undoubtedly interconnected; hence Mo Yan made use of these elements in order to criticize totalitarian states. The most basic and crucial element that is being explored is surely the Conceptual Integration, which provides Mo Yan with the tools necessary for creating satirical atmosphere.

These days I can point out an Audi, a Mercedes, a BMW, and a Toyota; I also know all about U.S. space shuttles and Soviet aircraft carriers. But at the time, I was a donkey, a 1958 donkey. This strange object, with its four rubber wheels, was clearly faster than me, at least on level ground. Allow me to repeat Mo Yan's comment: A goat can scale a tree, a donkey is a good climber. (Yan, 2006, p. 61)

Satire is described as "the literary art of diminishing or derogating a subject by making it ridiculous and evoking toward it attitudes of amusement, contempt, scorn, or indignation" (Abrams \& Harpham, 2009, p. 320). Satirical atmosphere is also established from the beginning of the novel. Mo Yan's writings are empowered by several interconnected themes and styles ranging from magical realism to black humor and satire. Marked by an extreme sense of comedic effect that makes many scenes duplicate short theatrical skits, Mo Yan's works employ various comic elements to build distinct narratives about China, amending the spectrum of the literary practice.

Fauconnier and Turner's claim that conceptual integration theory extends into multitudinous aspects of life turns out to be truly obvious in the domain of political satire. Satirists create a novel mental space (blended space) by utilizing satire in cartoons, literature, and film in order to embody the relation between a complex subject to a simpler concept. 
Therefore, it is obvious that personification and conceptual integration are utilized by Mo Yan in order to communicate his satirical message.

In each incarnation in the novel, Ximen Nao keep up connections with his family, following them over the next forty years. His animal personae allow him free rein for perception and remark. His adventures as a pig on the Ximen Village Production Brigade Apricot Garden Pig Farm open the door to satire, as giant pig ranches were one of Mao's great fizzled undertakings. As Ximen Nao's earthly manifestations change, so does his surroundings. The Cultural Revolution comes and goes, Mao dies. Capitalism again returns with excessive speed and greed. By the end, there are billionaires in mansions and beggars on the streets once again. The wheel has turned completely, and Ximen Nao has realized his lesson.

Finally, the analysis of the above results intended to make it clear that the novel is widely considered to be a critique or warning about the dangers of totalitarian states as well as the thirst and ambition for power. The analysis and discussion of the findings in the investigation illustrate that Mo Yan utilizes personification and conceptual integration in order to create a satirical atmosphere and to criticize totalitarian states.

\section{Conclusion}

\subsection{Summing-up and Conclusion}

"I have nothing against the Communist Party, and I definitely have nothing against Chairman Mao. I'm not opposed to the People's Commune or to collectivization. I just want to be left alone to work for myself" (Yan, 2006, p. 200).

Conceptual Integration Theory has from the very onset been especially inspirational to literary scholars who welcomed Turner's exploration of what he called the literary mind. Freeman applied the theory to certain types of anaphora in poetry (1997, pp. 7-28); Oakley (1998, pp. 321-360) utilized it in examination of a passage from the comic strip Maus; and stimulated by Turner's work (including his 1991 book "the Study of English in the Age of Cognitive Science"), and by Fauconnier's books, providing a mental space framework for examining literary texts as complete and coherent literary units.

"The development of the mental spaces theory has helped overcome one of the main obstacles to the linguistic analysis of literary texts, namely the question of context" (Dzeren-Glowacka, 2012, p. 194). For years, structuralists limited their analysis of literature to the text itself. For a long time, structuralists constrained their investigation of literature to the text itself. Furthermore, by moving the focus of attention in literary studies towards the reader - hermeneutics and reader response criticism - and the advancements first in the field of semiotics and pragmatics, and then of cognitive linguistics, it became quite evident that meaning lies mainly in the context of the words utilized and in the minds of the language users, rather than in the words themselves.

Margaret Freeman describes literary texts as "the products of cognizing minds and their interpretations as the products of other cognizing minds in the context of the physical and socio-cultural worlds in which they have been created and read" (qtd. in Dzeren-Glowacka, 2012, p. 194). All the three components of text analysis: the writer, the reader, and the text have naturally turned into the center of consideration in cognitive linguistics.

Conceptual Integration Theory offers a model of how meaning is formulated by mapping materials from mental spaces. These materials — cultural frames, exemplified schemata, relations, contextual knowledge - are combined into new blends, which hold the connections to their inputs, then establishing a network of mappings and projections. According to this theory, conceptual blending is an obvious human capacity that accommodate all significant results of meaning construction such as metaphor, language, religion, art, and so forth.

Mo Yan also utilized personification to facilitate access to the narrative of Life and Death Are Wearing Me Out and to communicate his message to readers against the political systems which he had seen in second half of the twentieth century. He uses personification to develop the plot and chooses animals and gives them human traits to show the pains that Chinese people suffered under Mao Zedong's leadership. Mo Yan may have a psychological motives in using this device, aiming at involving the reader in a cognitive mode with a view to enhance narration. Therefore, the semantic creativity in personification seems to be both linguistic and psychological, and in this case personification might be more functional than decorative.

Conceptual integrations, or blendings, are surrounding us in everyday life and they offer a model with which further understanding of our world, language and culture can take place. The pervasiveness of conceptual blending spreads to all aspects of life such as science, math, advertising and marketing, literature, poetry, linguistics, and so on. (Fauconnier \& Turner, 1994; 1998, pp. 133-187; 2003).

In the past few years, much of cognitive science concentrated on such mental capacities as memory, learning, symbolic thought, and language acquisition - the capacities in which the human mind most closely takes after a computer. But humans are more than computers, and the forefront investigation in cognitive science is increasingly focused on the creative aspects of the mind. The Conceptual Integration Theory is a landmark theory that exemplifies this new direction. The theory is now widely known in laboratories throughout the world; Fauconnier and Turner assert that all of our thinking processes consist of blends of metaphors based on simple bodily experiences. Then these blends themselves will be combined together into a new blended space which encompass our mental functioning in the society. This theory presents how blending, for instance, a child's entire development operates, and how it is affected by language, identity, and so forth. The result is an amazing, intriguing, and new view of how the mind works. 
Conceptual blending can be considered as a cognitive process or as a consequence of the learning process. As a cognitive process, conceptual blending is a backstage, or sub-conscious mental process, which enables one to construct meaning from distinct concepts that have no explicitly obvious connection to each other. Two concepts are combined into a third one which hold some properties of both original concepts, but not all of their properties. The common properties of the two original concepts provide the basis for an emerging concept that is different from either of the two original concepts.

However, the purpose of this study was to examine the nature of conceptual integrations as well as the way in which Mo Yan's construction of a satirical message in Life and Death Are Wearing Me Out was facilitated by the establishment of personification and blending. It has also been shown that the emergent structure of conceptual integration contains the components needed by Mo Yan in his critique of totalitarian states, and that the establishment of both the personification and the blending allow for this to happen. Considering the above discussion, it can be concluded that Mo Yan by utilizing personification and conceptual integration expressed his dissatisfaction with communist party and also criticized the totalitarian states.

\subsection{Suggestions for Further Research}

While this study offered a model that resides meaning in communicating minds, it nevertheless only concentrates on one cognitive semantic theory. However, studies in the similar field could explore the way in which our social nature gives rise to meaning construction. In this respect, further useful links to conceptual blending could be developed. As it is discussed, the pervasiveness of conceptual blending could clearly be observed in everyday life. We are dealing with conceptual blendings as we walk down the streets and look at advertisements on the billboards.

However, further studies could be done in relation to this topic by examining other works of literature, film, television shows, and even commercials so as to illustrate the pervasiveness of conceptual blending. Furthermore, numerous efforts could be conducted regarding the interdisciplinary studies between conceptual blending and film studies, literary discourse, comics, multimodal communications, and even political discourse.

\section{References}

Abrams, M. H., \& Harpham, G. G. (2009). A glossary of literary terms (9th ed.). Boston: Wadsworth Cengage Learning.

Árpád, K. (2007). Conceptual Integration in Sylvia Plath's "Getting There". Argumentum, 3, 1-11.

Brandt, L., \& Brandt, P. A. (2005). Making sense of a blend: A cognitive-semiotic approach to metaphor. Annual Review of Cognitive Linguistics, 3(1), 216-249.

Charteris-Black, J. (2005). Politicians and rhetoric : the persuasive power of metaphor. Houndmills, Basingstoke, Hampshire ; New York: Palgrave Macmillan.

Coulson, S. (2006). Semantic leaps : frame-shifting and conceptual blending in meaning construction. Cambridge: Cambridge University Press.

Dzeren-Glowacka, S. (2012). Formal and Conceptual Blending in Terry Pratchett's Discworld. UK-CLA, 1, 193-208.

Fauconnier, G., \& Turner, M. (1994). Conceptual projection and middle spaces. San Diego: UCSD Department of Cognitive Science.

Fauconnier, G., \& Turner, M. (1998). Conceptual integration networks. Cognitive science, 22(2), 133-187.

Fauconnier, G., \& Turner, M. (2003). The way we think: conceptual blending and the mind's hidden complexities. New York: BasicBooks.

Freeman, M. H. (1997). Grounded spaces: Deictic-self anaphors in the poetry of Emily Dickinson. Language and Literature, 6(1), 7-28.

Freeman, M. H. (2005). The poem as complex blend: conceptual mappings of metaphor in Sylvia Plath's 'The Applicant'. Language and Literature, 14(1), 25-44.

Grady, J., Oakley, T., \& Coulson, S. (1999). Blending and metaphor. AMSTERDAM STUDIES IN THE THEORY AND HISTORY OF LINGUISTIC SCIENCE SERIES 4, 101-124.

Lakoff, G., \& Johnson, M. (2003). Metaphors we live by. Chicago: University of Chicago Press.

Mo Yan. (n.d). BrainyQuote.com. Retrieved 11 July 2014, from

http://www.brainyquote.com/quotes/authors/m/mo_yan.html

Oakley, T. (1998). Conceptual blending, narrative discourse, and rhetoric. Cognitive linguistics, 9(4), 321-360.

Paxson, J. J. (1994). The poetics of personification. Cambridge: Cambridge University Press.

Starkey, L. B. (2004). How to Write Great Essays: LearningExpress.

Turner, M. (1998). The Literary Mind: The Origins of Thought and Language: Oxford University Press, USA.

Veale, T. (2002). Proceedings of TWWT 2002: The Way We Think. Compromise in Multi-Agent Blends, 23, 1-38.

Yan, M. (2006). Shengsi Pilao [Life and Death Are Wearing Me Out] (H. Goldblatt, Trans.). Beijing: Zuojia chubanshe. 